\title{
AKSELERASI PENDIDIKAN KARAKTER UNTUK MEWUJUDKAN REVOLUSI MENTAL
}

\author{
Rahmat Datau
}

\section{A. Pendahuluan}

Pendidikan karakter adalah suatu sistem penanaman nilai-nilai karakter kepada warga sekolah yang meliputi komponen pengetahuan, kesadaran atau kemauan, dan tindakan untuk melaksanakan nilai-nilai tersebut, baik terhadap Tuhan Yang Maha Esa (YME), diri sendiri, sesama, lingkungan, maupun kebangsaan sehingga menjadi manusia insan kamil. Dalam pendidikan karakter di sekolah, semua komponen (stakeholders) harus dilibatkan, termasuk komponenkomponen pendidikan itu sendiri, yaitu isi kurikulum, proses pembelajaran dan penilaian, kualitas hubungan, penanganan atau pengelolaan mata pelajaran, pengelolaan sekolah, pelaksanaan aktivitas atau kegiatan ko-kurikuler, pemberdayaan sarana prasarana, pembiayaan, dan ethos kerja seluruh warga dan lingkungan sekolah.

Terlepas dari berbagai kekurangan dalam praktik pendidikan, apabila dilihat dari standar nasional pendidikan yang menjadi acuan pengembangan kurikulum (KTSP), dan implementasi pembelajaran dan penilaian di sekolah, tujuan pendidikan sebenarnya dapat dicapai dengan baik. Pembinaan karakter juga termasuk dalam materi yang harus diajarkan dan dikuasai serta direalisasikan oleh peserta didik dalam kehidupan seharihari. Permasalahannya, pendidikan karakter di sekolah selama ini baru menyentuh pada tingkatan pengenalan norma atau nilai-nilai, dan belum pada tingkatan internalisasi dan tindakan nyata dalam kehidupan sehari-hari.

\section{B. Pembahasan}

Pendidikan karakter dapat diintegrasikan dalam pembelajaran pada setiap mata pelajaran. Materi pembelajaran yang berkaitan dengan norma atau nilai-nilai pada setiap mata pelajaran perlu dikembangkan, dieksplisitkan, dikaitkan dengan konteks kehidupan sehari-hari. Dengan demikian, pembelajaran nilai-nilai karakter tidak hanya pada tataran kognitif, tetapi menyentuh pada internalisasi, dan pengamalan nyata dalam kehidupan peserta didik seharihari di masyarakat.

Kegiatan ekstra kurikuler yang selama ini diselenggarakan sekolah merupakan salah satu media yang potensial untuk pembinaan karakter dan peningkatan mutu akademik peserta didik. Kegiatan Ekstra Kurikuler merupakan kegiatan pendidikan di luar mata pelajaran untuk membantu pengembangan peserta didik sesuai dengan kebutuhan, potensi, bakat, dan minat mereka melalui kegiatan yang secara khusus 
diselenggarakan oleh pendidik dan atau tenaga kependidikan yang berkemampuan dan berkewenangan di sekolah. Melalui kegiatan ekstra kurikuler diharapkan dapat mengembangkan kemampuan dan rasa tanggung jawab sosial, serta potensi dan prestasi peserta didik.

Berdasarkan grand desain pendidikan karakter yang dikembangkan oleh Depdiknas (2010), pendidikan karakter dalam diri peserta didik merupakan fungsi dari seluruh potensi individu manusia (kognitif, afektif, konatif, dan psikomotor) dalam konteks interaksi sosial cultural (dalam keluarga, sekolah dan masyarakat) yang berlangsung sepanjang hayat. Konfigurasi pendidikan karakter, dengan demikian dapat dilompokkan ke dalam empat konfigurasi psikologis dan sosiokultural, yaitu: Olah Hati (Spiritual and Emotional Development), Olah Pikir (Intellectual Development), Olah Raga dan Kinestetik (Physical and Kinesthetic Development), dan Olah Rasa dan Karsa (Affective and Creativity Development) (Sofan Amri, Ahmad Jauhari, Tatik Elisah, 2010: 5-6).

Dengan demikian, maka ruang lingkup pendidikan karakter dapat dikaitkan dengan keempat konfigurasi di atas, yakni pendidikan dalam aspek emosional dan spiritual, pendidikan intelektual, pendidikan fisik dan kinestetik, dan pendidikan sikap dan kreatifitas. Kesemuanya itu diarahkan pada pembetukan karakter utama melalui proses pendidikan. Karakter utama yang diharapkan itu antara lain: Religius, Jujur, Toleransi, Disiplin, Kerja keras, Kreatif, Mandiri, Demokratis, Rasa Ingin Tahu, Semangat Kebangsaan, Cinta Tanah Air, Menghargai Prestasi, Bersahabat/Komunikatif, Cinta Damai, Gemar Membaca, Peduli Lingkungan, Peduli Sosial, Tanggung Jawab. Proses pembentukannya bisa di mana saja, baik di rumah, di sekolah, maupun di masyarakat, sehingga peserta didik akan dapat memiliki karakter yang diharapkan, melalui proses pendidikan.

Di lihat dari segi komponennya, pendidikan karakter dalam pandangan Thomas Lickona (1992: 21) menekankan pentingnya tiga komponen karakter yang baik (components of good character) yaitu moral knowing atau pengetahuan tentang moral, moral feeling atau perasaan tentang moral dan moral action atau perbuatan bermoral. Komponen tersebut dapat digambarkan sebagai berikut: 


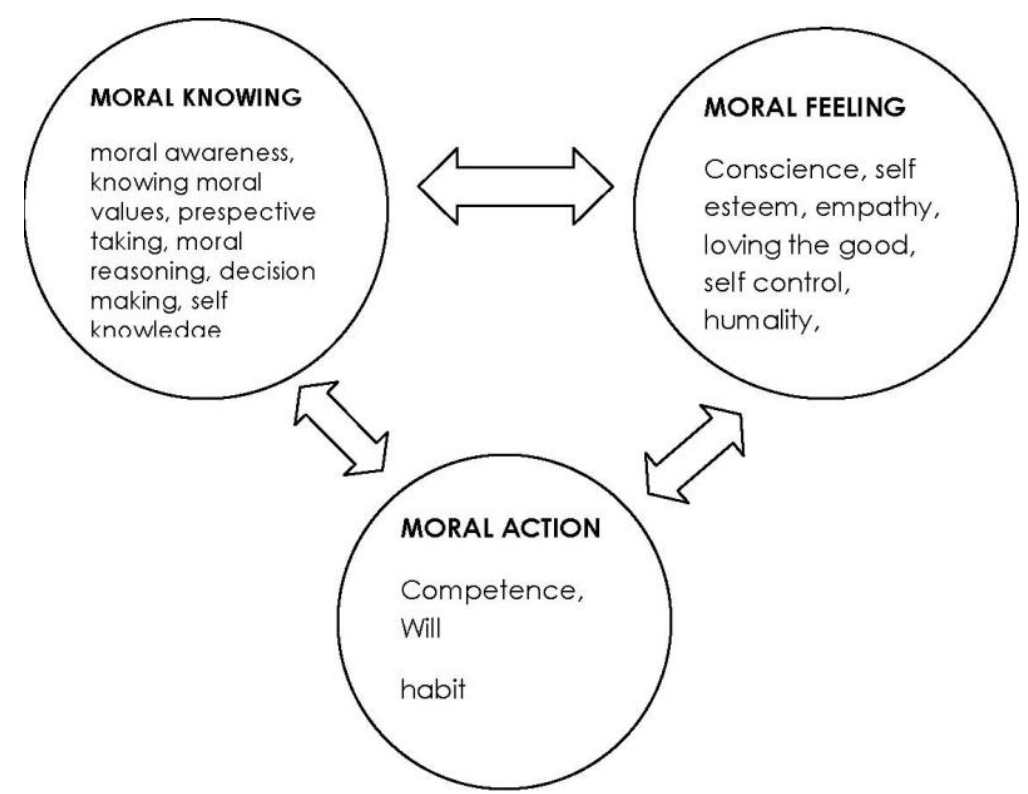

Sumber: Lickona (1991: 11)

Kemudian dalam desain pelaksanaan pendidikan karakter, menurut Doni Koesoma (2011: 2) setidaknya ada tiga desain, yakni: pertama, desain pendidikan karakter berbasis kelas. Desain ini berbasis pada hubungan guru sebagai pendidik dan siswa sebagai pembelajar di dalam kelas. Konteks pendidikan karakter adalah proses hubungan komunitas kelas dalam konteks pembelajaran. Relasi antara guru dengan pembelajar bukan monolog, melainkan dialog dengan banyak arah.

Kedua, desain pendidikan karakter berbasis kultur sekolah. Desain ini membangun budaya sekolah yang mampu membentuk karakter anak didik dengan bantuan pranata sosial sekolah agar nilai tertentu terbentuk dan terbatinkan dalam diri siswa. Ketiga, desain pendidikan karakter berbasis komunitas. Dalam mendidik, komunitas sekolah negeri maupun swasta tidak berjuang sendirian. Kalau ketiga komponen bekerjasama melaksanakan dengan baik, maka akan terbentuk karakter bangsa yang kuat.

Megawangi \& Williams (2007) merumuskan delapan karakter dasar yang menjadi tujuan pendidikan karakter. Delapan karakter tersebut adalah; (1) cinta kepada Tuhan dan semesta beserta isinya, (2) tanggung jawab, disiplin dan mandiri, (3) jujur, (4) hormat dan santun, (5) kasih sayang, peduli, dan kerja sama, (6) percaya diri, kreatif, kerja keras dan pantang menyerah, (7) keadilan dan kepemimpinan, baik dan rendah hati, dan (8) toleransi, cinta damai dan persatuan.

Pelaksanaan pendidikan karakter dalam mata pelajaran mengembangkan nilai-nilai karakter religius, jujur, toleransi, disiplin, kerja keras, kreatif, mandiri, demokratis, rasa ingin tahu, semangat kebangsaan, cinta tanah air, menghargai prestasi, bersahabat/komunikatif, cinta damai, gemar membaca, peduli lingkungan, peduli sosial, dan tanggung jawab dalam pembelajaran di kelas. Nilai-nilai 
karakter disesuaikan dengan KD dan indikator. Dalam pelaksanaan pendidikan karakter dari Kemendiknas dapat dilaksanakan kegiatan yang sudah ada kemudian dikuatkan, dan juga dapat menyelengarakan kegiatan baru.

Dari nilai-nilai karakter yang dikembangkan Kemendiknas, pelaksanaan Pendidikan Karakter semuanya sudah dilaksanakan sesuai dengan KD dan indikator materi yang disampaikan guru. Kedua, pelaksanaan pendidikan melalui kegiatan ekstrakulikuler. Sembilan program yang dikembangkan Rohis menurut peneliti sangat baik untuk pelaksanaan Pendidikan Karakter, khususnya untuk penananaman nilai karakter religius, mandiri, rasa ingin tahu, gemar membaca, peduli sosial.

Dalam pelaksanaan kurikulum di setiap satuan pendidikan menggunakan prinsip-prinsip sebagai berikut: Pertama, Pelaksanaan kurikulum didasarkan pada potensi, perkembangan dan kondisi peserta didik untuk menguasai kompetensi yang berguna bagi dirinya. Dalam hal ini peserta didik harus mendapatkan pelayanan pendidikan yang bermutu, serta memperoleh kesempatan untuk mengeskpresikan dirinya secara Islami, dinamis dan menyenangkan; Kedua, Kurikulum dilaksanakan dengan menegakkan kelima pilar belajar, yaitu: a) belajar untuk beriman dan bertakwa kepada Allah SWT; b) belajar untuk memahami dan menghayati; c) belajar untuk mampu melaksanakan dan berbuat secara efektif; d) membangun dan menemukan jati diri, melalui proses pembelajaran yang aktif, kreatif, efektif, dan menyenangkan; Ketiga, Pelaksanaan kurikulum memungkinkan peserta didik mendapatkan pelayanan yang bersifat perbaikan, pengayaan, dan/atau percepatan sesuai dengan potensi, tahap perkembangan, dan kondisi peserta didik dengan tetap memperhatikan keterpaduan pengembangan pribadi peserta didik yang berdimensi ketauhidan, keindividuan, kesosialan, dan moral. Keempat, Kurikulum dilaksanakan dalam suasana peserta didik dan pendidik yang saling menerima dan menghargai, akrab, terbuka, dan hangat dengan prinsip uswatun hasanah, ing ngarsa sung tulada tut wuri handayani, ing madia mangun karsa, tut wuri handayani (di depan memberikan contoh dan teladan, di tengah membangun semangat dan prakarsa, di belakang memberikan daya dan kekuatan) dalam konteks amar ma'ruf nahi munkar. Kelima, Kurikulum dilaksanakan dengan menggunakan pendekatan multistrategi dan multimedia, sumber belajar dan teknologi yang memadai dan memanfaatkan lingkungan sekitar sebagai sumber belajar, dengan prinsip alam terkadang menjadi guru (semua yang terjadi, tergelar dan berkembang di masyarakat dan lingkungan sekitar serta lingkungan alam semesta dijadikan sebagai sumber belajar, contoh dan teladan. Keenam, Kurikulum dilaksanakan dengan mendayagunakan kondisi alam, sosial dan budaya serta kekayaan daerah untuk keberhasilan pendidikan dengan 
muatan seluruh bahan kajian optimal. Ketujuh, Kurikulum yang mencakup seluruh komponen kompetensi mata pelajaran, muatan lokal dan pengembangan diri, diselenggarakan dalam keseimbangan, keterkaitan, dan kesinambungan yang cocok dan memadai antar kelas dan jenis serta jenjang pendidikan.

Pembelajaran merupakan bentuk konkret atau realisasi kurikulum sebagai dukumen tertulis di sekolah atau di kelas, maka aktivitas pembelajaran yang relevan dilaksanakan guru untuk pembentukan insan berkarakter tentu tidak dapat dilepaskan dari karakteristik kurikulum yang berlaku di sekolah, mengingat posisi kurikulum sebagai jantungnya pendidikan, maka sudah seharusnya kurikulum saat ini memberikan perhatian yang lebih besar pada pendidikan karakter. Dengan demikian, apa pun aktivitas pembelajaran yang diupayakan guru haruslah mampu memfasilitasi pembentukan dan pengembangan peserta didik berkarakter. Salah satu cara yang relevan diterapkan adalah pengintegrasian karakter atau nilainilai ke dalam kegiatan pembelajaran setiap mata pelajaran yang tertera dalam kurikulum sekolah. Atas pertimbangan tersebut, maka pendidikan karakter tidak merupakan pelajaran yang berdiri sendiri, tetapi diintegrasikan dalam kurikulum dan berfungsi menjadi penguat kurikulum yang sudah ada.

Pengintegrasian nilai-nilai

karakter ke dalam kegiatan pembelajaran berarti memadukan, memasukkan, dan menerapkan nilainilai yang diyakini baik dan benar dalam rangka membentuk, mengembangkan, dan membina tabiat atau kepribadian peserta didik sesuai jati diri bangsa tatkala kegiatan pembelajaran berlangsung. Materi pembelajaran yang berkaitan dengan norma atau nilai pada setiap pelajaran perlu dikembangkan, diekplisitkan, dikaitkan dengan konteks kehidupan sehari-hari. Dengan demikian, pembelajaran nilai-nilai karakter tidak hanya pada tataran kognitif tetapi menyentuh pada pengalaman nyata dalam kehidupan peserta didik seharihari di masyarakat. setiap guru diharapkan dapat menjadi guru pendidikan karakter dan setiap guru seharusnya berkompeten untuk mendidik karakter peserta didiknya, artinya setiap guru mata pelajaran memiliki tugas dan tanggung jawab untuk mendidik karakter siswanya.

Usaha pembentukan watak melalui sekolah juga efektif melalui kurikulum tersembunyi seperti: 1) Penerapan tata tertib secara konsekuen, hal ini bertujuan mendidik dan melatih siswa unutk brdisiplin dan patuh pada aturan. 2) Upacara Bendera, kegiatan ini merupakan wahana yang yang menampilkan pesan tersembunyi dalam membentuk karakter cinta tanah air pada siswa. 3) Senantiasa mengumandangkan lagu-lagu wajib Kebangsaan. Pesan yang tersembunyi dari pembiasaan ini adalah pembentukan karakter dan jiwa patriotik kebangsaan. 4) Menyanyikan lagu "Sang Surya" setiap kegiatan SMA Negeri I Tilango, dengan penuh 
penghayatan, akan menumbuhkan karakter cinta agamanya, Rasulnya dan SMA Negeri I Tilango untuk taat dan menegakkan ajarannya. 5) Memasang gambar Tokoh dan Pahlawan Nasional seperti Ir. Soekarno, Jendral Soedirman,

RA Kartini, dan tokoh lain, dimaksudkan untuk menjadi panutan dan siswa meneladaninya. 6) Penampilan guru. Perbuatan Guru harus baik, tutur katanya benar, sopan, pakaiannya rajin kerena akan ditiru siswanya. Dengan kata lain seluruh lingkungan sekolah Pendidik, Tenaga Kependidikan harus mampu menjadi "UswahHasanah".

\section{PENUTUP}

1. Karakter mencakup pengertian, kepedulian, dan tindakan berdasarkan nilai-nilai etika, meliputi aspek kognitif, emosional, dan perilaku dari kehidupan moral. Karakter terbentuk dengan dipengaruhi oleh paling sedikit 5 faktor, yaitu: temperamen dasar, keyakinan, wawasan, motivasi hidup dan perjalanan. Karakter yang dapat membawa keberhasilan yaitu empati, tahan dan beriman.

2. Pendidikan karakter adalah pendidikan budi pekerti plus, yaitu yang melibatkan aspek pengetahuan (cognitive), perasaan (feeling), dan tindakan (action). Pendidikan karakter merupakan berbagai usaha yang dilakukan oleh para personil sekolah, bahkan yang dilakukan bersama-sama dengan orang tua dan anggota masyarakat, untuk membantu siswa agar menjadi atau memiliki sifat peduli, berpendirian, dan bertanggung jawab.

3. Penggunaan media pembelajaran berbasis keterampilan proses memiliki beberapa keuntungan terutama terkait dengan pendidikan karakter diantaranya: (1) pembelajaran mata pelajaran berbasis keterampilan proses memungkinkan peserta didik dapat terlibat aktif secara intelektual, manual, dan sosial. (2) pembelajaran berbasis keterampilan proses memungkinkan dapat dikembangkan sikap ilmiah pada peserta didik seperti: kejujuran, kesabaran, keterbukaan, ketelitian, kemandirian, sikap menghargai orang lain, disiplin dan lain-lain. Sikap ilmiah yang berkembangkan setelah melakukan keterampilan proses tersebut merupakan sikap dasar dalam membangun karakter yang kuat pada peserta didik. 


\section{DAFTAR PUSTAKA}

Koesoema, A. D. 2007. Pendidikan Karakter: Strategi Mendidik Anak di Zaman Global. Jakarta: PT. Gramedia Widiasarana Indonesia.

Koesoema, A. D.. 2009. Guru Karakter di Zaman Keblinger. Jakarta: Penerbit PT Grasindo.

Koesoema, A. D.. 2010a. Pendidikan Karakter Integral. Harian Kompas Edisi Kamis, 11 Februari 2010

Asrin. 2009. Profesionalisme Manajemen

Pendidikan. Gorontalo: Ideas Publishing

Abimanyu, Soli dan Manrihu, Thayeb. 1996. Tehnik dan Laboratorium Konseling. Jakarta: Depdikbud Dirjen Dikti.

Borck, L.E, dan Farveett, S.B. 1982. Learning Counseling and Problem Solving Skills. New York: The Hawarth Press.

Brammer, L.M dan Shostrom, E.L. 1982. Therapeutic Psychology: Fundamental of Counseling and Psychoterapy: Fourth Edition. New Jersey: Prentice Hall Inc.

Brammer, L.M. 1985. The Helping Relationship;Process and Skills: 3ed. New Jersey: Prentice Hall Inc.

BSNP, 2006, Panduan Penyusunan Kurikulum Tingkat Satuan Pendidikan (KTSP) Jenjang Pendidikan Dasar dan Menengah , Jakarta , Depdiknas

Capuzzi, D \& Gross, D.R. Counseling \& Psychotherapy; Theories and Interventions. New Jersey: Merril Prentice Hall.
Carter McNamara. " Organizational Culture". http://www.mapnp.org/library /orgthry/culture/culture.htm

The Management Assistance Program for Nonprofits.

Corey, Gerald. 2004. Theory and Practice of Counseling and Psychotherapy. Monterey, California : Brooks/Cole Publishing Company

Corey, Gerald. 2005. Theory and Practice of Counseling and Psychotheraphy: Seventh edition. Belmont, CA: Brooks/Cole-Thompson Learning Covey, Stephen. 1997. Eight Habit; From Goodness to Greatness. Jakarta: P.T. Gramedia.

Depdiknas, 2006, Peraturan Menteri Pendidikan Nasional Republik Indonesia Nomor 22 Tahun 2006, Tentang Standar Isi Untuk Satuan Pendidikan Dasar dan Menengah, Depdiknas, Jakarta

Depdiknas, 2006, Peraturan Menteri Pendidikan Nasional Republik Indonesia Nomor 23 Tahun 2006, Tentang Standar Kompetensi Lulusan Untuk Satuan Pendidikan Dasar dan Menengah, Depdiknas, Jakarta, Depdiknas

Depdiknas, 2006, Peraturan Menteri Pendidikan Nasional Republik Indonesia Nomor 24 Tahun 2006, Tentang Pelaksanaan Permen Diknas Nomor 22 Tentang Standar Isi Untuk Satuan Pendidikan Dasar dan Menengah dan Permen Nomor 23 Tentang Standar Kompetensi Lulusan Untuk Satuan Pendidikan Dasar 